\title{
Forty years without mental hospitals in Italy
}

\author{
Corrado Barbui ${ }^{1}$, Davide Papola ${ }^{1 *}$ (D) and Benedetto Saraceno ${ }^{2}$
}

\begin{abstract}
In 1978 Italy implemented Law Number 180, the reform law that blocked all new admissions to public mental hospitals. After 40 years without mental hospitals, we aim at understanding the consequences of the Italian reform in terms of mental health care facility and staff availability. We compared the organization of the Italian mental health system with that of countries belonging to the Group of 7 (G7) major advanced economies. Italy has nearly 8 psychiatrists, 20 nurses, 2 social workers and less than 3 psychologists per 100,000 population, while for example in France there were 22 psychiatrists, in Japan 102 nurses, in the United States 18 social workers, and in Canada and France more than 45 psychologists per 100,000 population. In terms of inpatient facilities, no beds in mental hospitals were available in Italy, while in the other G7 countries mental hospital beds ranged from 8 in the United Kingdom to 204 in Japan per 100000 population. In Italy there were fewer beds for acute care in general hospitals but more beds in community residential facilities than in the other G7 countries. Service use data showed variability in the provision of mental health care throughout the country. Soon after the implementation of the Italian reform the absolute number of compulsory admissions progressively declined, from more than 20,000 in 1978 to less than 9000 in 2015. Alongside the progressive decline of psychiatric beds imposed by Law 180, the age-adjusted suicide rate remained stable, ranging from 7.1/100,000 population in 1978 to $6 \cdot 3 / 100,000$ population in 2012 . The population of psychiatric patients placed in Italian forensic psychiatric hospitals progressively declined. During the last 40 years without mental hospitals, Italy has seen a progressive consolidation of a community-based system of mental health care. We highlighted, however, reasons for concern, including a decreasing staffing level, a potential use of community residential facilities as long-stay residential services, a still too high variability in service provision across the country, and lack of national data on physical restraints. At a national level, the resources allocated to mental health care are lower in Italy than in other high-income countries.
\end{abstract}

Keywords: Italy, Reform law 180, Mental health, Community care

\section{Background}

A radical change in the organization of mental health care occurred in Italy in 1978 as a consequence of the implementation of the Italian Law Number 180, the reform law that marked the transition from a hospitalbased system of care to a model of community mental health care (Box 1) [1-8]. Law 180 blocked all new admissions to public mental hospitals, with immediate

\footnotetext{
${ }^{*}$ Correspondence: candido09@hotmail.it

${ }^{1}$ WHO Collaborating Centre for Research and Training in Mental Health

and Service Evaluation, Department of Neuroscience, Biomedicine and Movement Sciences, Section of Psychiatry, University of Verona,

Policlinico GB Rossi, Piazzale Scuro, 10, 37134 Verona, Italy

Full list of author information is available at the end of the article
}

effect (i.e. from 1978), as well as readmissions, 2 years later. Consequently, the psychiatric hospital population (78,538 individuals in 1978) dropped by $53 \%$ between 1978 and 1987, further declined to 7704 in 1998, and the final dismantling was completed by year $2000[9,10]$.

After 40 years of community mental health care, here we provide an overview of the mental health system in Italy, with emphasis on understanding the consequences of the Italian reform in terms of mental health care facility and staff availability. Using available data taken from both international and national sources (Box 2) [11-15], we compared the organization of the Italian mental health system with that of countries belonging to the Group of 7 (G7) major advanced economies. 
Additionally, we described trends in compulsory admissions and suicide rates in Italy in the 40 years after the implementation of Law 180.

\section{Box 1. Summary of the main characteristics of the 1978} Italian psychiatric reform

The main principle of Law 180 is that patients with mental disorders have the right to be treated the same way as patients with other diseases, which means the following:

Acute mental health conditions have to be managed in psychiatric wards located in general hospitals. These wards cannot exceed 15 beds.

Treatments should be provided on a voluntary basis, with compulsory admissions reserved for the following specific circumstances: (1) an emergency intervention is needed; (2) the patient refuses treatment; (3) alternative community treatment is impossible.

Compulsory admissions need to be formally authorized by the Mayor and can only be undertaken in general hospital psychiatric wards.

New community-based services were to be established to provide mental health care to the population of a given catchment area.

Gradual closure of public mental hospitals by blocking all new admissions.

\section{Box 2. Data source}

We used the Organisation for Economic Co-operation and Development (OECD) database to gather information on demographic and economic indicators, psychiatric bed availability and age-standardised suicide rates for Italy and the other G7 countries [11].

The WHO Global Health Observatory [12] and the WHO Mental Health ATLAS-2014 repository [13] were used to extract data on inpatient and outpatient resources for mental health care (both public and private) in Italy and in the other G7 countries. WHO definitions of mental health staff, inpatient and outpatient facilities were used. For inpatient facilities, the following WHO categories were used: mental hospitals (public and private non-profit and for-profit specialized hospital-based facilities that provide inpatient care and long-stay residential services for people with mental disorders), psychiatric wards in general hospitals (public and private non-profit and for-profit psychiatric units usually located within general hospitals that provide inpatient care for the management of acute mental disorders), community residential facilities (public and private non-profit and for-profit nonhospital, community-based mental health facilities that provide overnight residence for people with mental disorders).

From the recently implemented Italian national mental health information system data on the availability and use of mental health facilities (both public and private) were gathered for the year 2015 [14]. The following information was extracted for each Italian region: treated prevalence of any mental disorders (number of individuals with at least one contact with psychiatric services during 2015/10,000 population); treated incidence of any mental disorders (number of individuals with a first ever contact with psychiatric services during 2015/10,000 population); rate of individuals under the care of mental health outpatient facilities (per 10,000 population); rate of individuals under the care of day treatment facilities (per 10,000 population); admissions to community residential facilities (per 10,000 population); admissions to psychiatric wards of general hospitals (per 10,000 population); rate of compulsory admissions (per 10,000 population); proportion of outpatients visits within 30 day after hospital discharge.

As additional source of information, we used the Italian Central Institute of Statistics (ISTAT) data to describe the total number of compulsory admissions and the proportion of all psychiatric admissions that were compulsory from 1978 onwards [15]. Data released from the Commission on psychiatric forensic facilities were used to compute the number of psychiatric patients placed in forensic psychiatric hospitals from 1978 onwards [16].

\section{Italy in comparison with the other $\mathbf{G 7}$ countries}

Italy is the fourth most populous European state after Germany, France and the United Kingdom. It hosts a growing proportion of foreign population, which is approaching 10\%, as in Germany (Table 1). In 2014, the number of healthy life years at birth was estimated at 83 years, similar to Japan and higher than the other G7 countries. The unemployment rate in 2016 was close to $12 \%$, with a gross domestic product much lower than the other G7 countries. In 2011, the proportion of government expenditures on mental health was half than Germany or France (Table 1).

Italy, in comparison with the other G7 countries, has fewer human resources for mental health care (Table 2). According to WHO ATLAS-2014, there were nearly 8 psychiatrists, 20 nurses, 2 social workers and less than 3 psychologists per 100,000 population, while for example in France there were 22 psychiatrists, in Japan 102 nurses, in the United States 18 social workers, and in Canada and 
Table 1 Demographic and economic indicators for Italy and the other countries belonging to the Group of 7 (G7) major advanced economies (OECD data)

\begin{tabular}{|c|c|c|c|c|c|c|c|c|}
\hline & Canada & France & Germany & Italy & Japan & UK & USA & Year \\
\hline Population (million persons) & 35.54 & 64.06 & 80.89 & 60.44 & 127.51 & 63.65 & 318.85 & 2014 \\
\hline Foreign population (\% of population) & NA & NA & 9.29 & 8.11 & 1.62 & 7.70 & 6.96 & 2013 \\
\hline Healthy life expectancy at birth (years) & NA & 82.40 & 81.20 & 83.20 & 83.70 & 81.40 & 78.80 & 2014 \\
\hline Unemployment rate (\% of labour force) & 6.99 & 10.05 & 4.10 & 11.68 & 3.11 & 4.80 & 4.86 & 2016 \\
\hline Gross domestic product (total, US dollars/capita) & 44,025 & 41,489 & 48,839 & 38,146 & 41,534 & 42,651 & 57,325 & 2016 \\
\hline $\begin{array}{l}\text { Government expenditures on mental health (\% of } \\
\text { total expenditure on health) }\end{array}$ & 7.20 & 12.91 & 11.00 & 5.00 & 4.94 & NA & NA & 2011 \\
\hline
\end{tabular}

OECD Organisation for Economic Co-operation and Development

$N A$ not available

Table 2 Staff availability and resources for mental health care in Italy and in the other G7 countries

\begin{tabular}{|c|c|c|c|c|c|c|c|}
\hline & Canada & France & Germany & Italy & Japan & UK & USA \\
\hline \multicolumn{8}{|l|}{ Staffa $^{a}$} \\
\hline Psychiatrists working in mental health sector (per 100,000) & 12.61 & 22.35 & 15.23 & 7.83 & 10.1 & 14.63 & 12.40 \\
\hline Nurses working in mental health sector (per 100 000) & 65.0 & 86.21 & 56.06 & 19.28 & 102.55 & 67.35 & 3.07 \\
\hline Social workers working in mental health sector (per 100 000) & NA & 3.83 & NA & 1.93 & 6.06 & 1.99 & 17.93 \\
\hline Psychologists working in mental health sector (per 100 000) & 46.56 & 47.9 & NA & 2.58 & 3.99 & 12.83 & 29.03 \\
\hline \multicolumn{8}{|l|}{ Inpatient facilities ${ }^{b}$} \\
\hline Beds for mental health in general hospitals (per 100 000) & NA & 22.72 & 41.08 & 10.95 & 73.12 & 50.63 & 14.36 \\
\hline Beds in community residential facilities (per 100 000) & NA & NA & NA & 46.41 & 16.23 & 2.28 & 22.29 \\
\hline Beds in mental hospitals (per 100 000) & 31.38 & 71.81 & 47.62 & 0 & 204.4 & 7.99 & 19.44 \\
\hline \multicolumn{8}{|l|}{ Outpatient facilities ${ }^{b}$} \\
\hline Mental health outpatient facilities (per 100,000) & NA & 5.75 & 30.32 & 1.43 & 2.31 & 4.94 & 1.95 \\
\hline Day treatment facilities (per 100,000) & NA & 3.50 & 0.61 & 1.34 & 1.05 & 2.88 & NA \\
\hline
\end{tabular}

NA not available

a From WHO Global Health Observatory (GHO)

b From WHO ATLAS

France more than 45 psychologists per 100,000 population (Table 2).

In terms of inpatient facilities, no beds in public mental hospitals were available in Italy, as required by Law 180 , while in the other G7 countries mental hospital beds showed high variability, ranging from 8 in the United Kingdom to 204 in Japan per 100,000 population. In Italy there were fewer beds for acute care in general hospitals than in the other G7 countries, with Japan having more than 70 beds in general hospitals and Italy around $10 / 100,000$ population. However, In Italy the rate of beds in community residential facilities was higher than in other countries where this information was available (Table 2).

\section{Trends in public health indicators}

Soon after the implementation of the Italian reform the absolute number of compulsory admissions progressively declined, from more than 20,000 in 1978 to less than 9000 in 2015. Similarly, the proportion of psychiatric admissions that were compulsory progressively declined from 1978 to 2005 , and remained stable thereafter, accounting for less than $5 \%$ of all psychiatric admissions (Fig. 1).

Figure 2 describes the age-adjusted suicide rate in Italy from 1978 onwards, alongside the progressive decline of psychiatric beds imposed by Law 180. In 1978 there were 7.1 suicides per 100,000 population, while in 2012 there were 6.3 suicides per 100,000 population, with the highest rate in 1985 (8.8 suicides per 100,000) and the lowest in $2006(5.6 / 100,000)$. Lack of a clear relationship between psychiatric bed availability and suicides was also suggested by Fig. 3, where psychiatric beds for the G7 countries are reported alongside the national rate of suicides. In Japan the rate of suicide was the highest among the G7 countries, despite more than 250 psychiatric beds per 100,000 population, while in the United States there were high suicide rates with relatively few psychiatric 


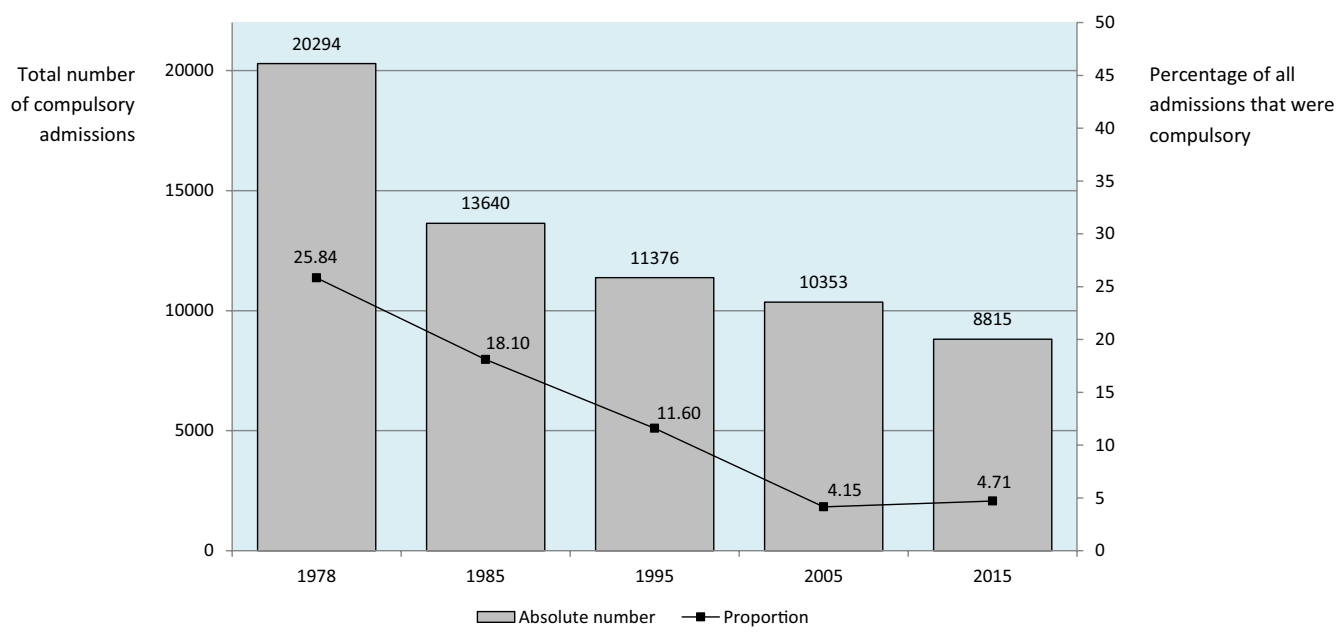

Fig. 1 Compulsory psychiatric admissions in Italy, 1978-2015 (ISTAT data)

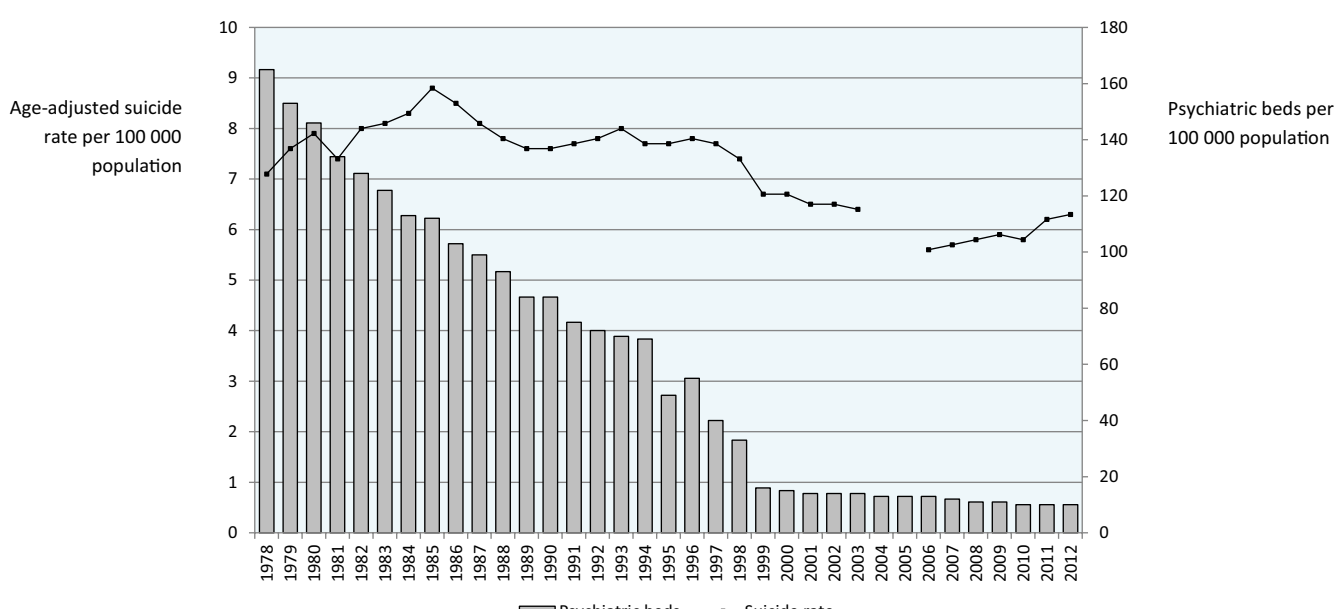

$\square$ Psychiatric beds $\rightarrow$ - Suicide rate

Fig. 2 Availability of acute-care psychiatric beds in Italy and age-standardised suicide rates from 1978 to 2012 (OECD data, 2004 and 2005 are missing)

beds. The United Kingdom showed a situation similar to Italy, with few beds and relatively low suicide rates.

Unfortunately, there is little epidemiological data on the population of psychiatric patients placed in forensic psychiatric hospitals from 1978 onwards. In 1980, the population comprised 1424 people, in 1987 there were 977 people and in 2012 there were 1264 people [16]. In 2016, after the phasing out of forensic psychiatric hospitals, there were 541 individuals placed in newly developed residential facilities providing intensive mental health care to socially dangerous individuals with mental disorders [16]. Additionally, there were 201 individuals with mental disorders placed in psychiatric units in prison, yielding an overall number of 742 people for the year 2016 [16].

\section{Service use data for mental health care in Italian regions}

In Table 3 service use data for mental health care in Italy is presented for the year 2015. Substantial variability in the provision of mental health care can be observed throughout the country. For example, the treated prevalence of mental disorders, a proxy indicator of the coverage capacity of community psychiatric services, ranged from 205 individuals per 10,000 population in Emilia Romagna (north of Italy) to 108 in Basilicata (south). Similar differences were observed for the treated incidence of 


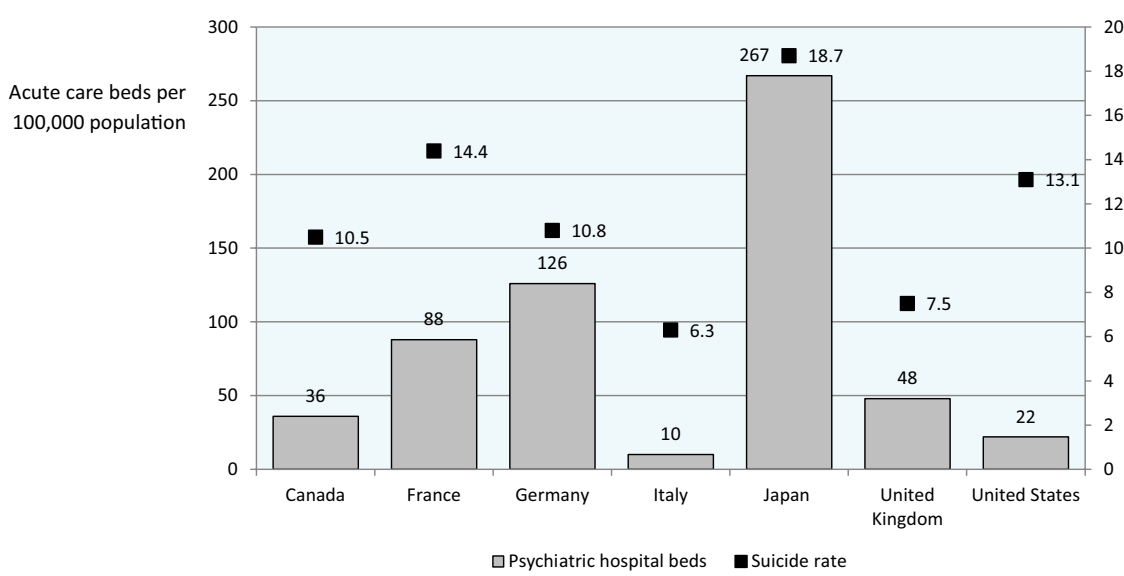

Age-adjusted

suicide rate per

100000 population

Psychiatric hospital beds

Fig. 3 Availability of acute-care psychiatric beds and age-standardised suicide rates in the G7 countries (OECD data)

Table 3 Treated prevalence and treated incidence of mental disorders, and service use data for mental health care in Italian regions, year 2015 (Italian national mental health information system data)

\begin{tabular}{|c|c|c|c|c|c|c|c|c|}
\hline \multirow{2}{*}{$\begin{array}{l}\text { Italian } \\
\text { region } \\
\text { (north } \\
\text { to south) }\end{array}$} & \multicolumn{7}{|c|}{ Rate per 10,000 population } & \multirow{2}{*}{$\begin{array}{l}\text { Percentage } \\
\text { Outpatient } \\
\text { visits } \\
\text { within } 30 \text { days } \\
\text { after hospital } \\
\text { discharge }\end{array}$} \\
\hline & $\begin{array}{l}\text { Treated } \\
\text { prevalence } \\
\text { of mental } \\
\text { disorders }\end{array}$ & $\begin{array}{l}\text { Treated } \\
\text { incidence } \\
\text { of mental } \\
\text { disorders } \\
\text { (first-ever } \\
\text { cases) }\end{array}$ & $\begin{array}{l}\text { Individuals } \\
\text { under the care } \\
\text { of mental } \\
\text { health } \\
\text { outpatient } \\
\text { facilities }\end{array}$ & $\begin{array}{l}\text { Individuals } \\
\text { under the care } \\
\text { of day } \\
\text { treatment } \\
\text { facilities }\end{array}$ & $\begin{array}{l}\text { Admissions } \\
\text { to community } \\
\text { residential } \\
\text { facilities }\end{array}$ & $\begin{array}{l}\text { Admissions } \\
\text { to psychiatric } \\
\text { wards }\end{array}$ & $\begin{array}{l}\text { Compulsory } \\
\text { admissions }\end{array}$ & \\
\hline Piemonte & 163.68 & 67.64 & 164.13 & 8.79 & 5.34 & 24.20 & 1.37 & 52.1 \\
\hline Valle D'Aosta & NA & NA & NA & NA & NA & 30.17 & 2.99 & NA \\
\hline Lombardia & 176.65 & 46.52 & 172.54 & 6.70 & 5.71 & 23.78 & 0.96 & 55.3 \\
\hline Bolzano & NA & NA & NA & NA & NA & 40.19 & 0.22 & NA \\
\hline Trento & 165.96 & 57.54 & 177.27 & 4.77 & 3.70 & 19.26 & 0.95 & 86.7 \\
\hline Veneto & 143.40 & 67.99 & 142.29 & 13.98 & 4.56 & 28.69 & 0.98 & 34.9 \\
\hline $\begin{array}{l}\text { Friuli Venezia } \\
\text { Giulia }\end{array}$ & 116.52 & 120.20 & 113.86 & 10.45 & 2.95 & 6.34 & 0.43 & 69.9 \\
\hline Liguria & 175.33 & 131.32 & 176.26 & 6.66 & 10.35 & 37.46 & 1.19 & 41.7 \\
\hline $\begin{array}{l}\text { Emilia } \\
\text { Romagna }\end{array}$ & 205.82 & 79.38 & 206.25 & 5.54 & 14.27 & 26.78 & 2.64 & 56.9 \\
\hline Toscana & 110.49 & 39.01 & 110.66 & 3.07 & 3.62 & 23.23 & 1.16 & 49.3 \\
\hline Umbria & 164.89 & 48.03 & 184.12 & 3.74 & 9.79 & 10.48 & 1.94 & 30.1 \\
\hline Marche & 158.94 & 44.05 & 168.84 & 4.35 & 8.84 & 24.25 & 5.68 & 49.7 \\
\hline Lazio & 138.60 & 76.39 & 131.45 & 5.59 & 10.13 & 17.31 & 1.46 & NA \\
\hline Abruzzo & 142.41 & 66.83 & 141.82 & 4.37 & 3.88 & 24.50 & 1.49 & 32.1 \\
\hline Molise & 165.10 & 71.77 & 167.24 & 2.06 & 5.05 & 22.00 & 1.61 & 63.6 \\
\hline Campania & 139.39 & 54.05 & 153.06 & 3.47 & 1.56 & 9.06 & 1.90 & 57.8 \\
\hline Puglia & 167.58 & 79.69 & 159.83 & 4.27 & 6.25 & 17.35 & 2.07 & 47.3 \\
\hline Basilicata & 107.63 & 47.98 & 135.73 & 2.53 & 5.94 & 18.75 & 0.72 & NA \\
\hline Calabria & 161.34 & 105.85 & 222.09 & 0.30 & 0.37 & 16.38 & 2.10 & 50.0 \\
\hline Sicilia & 186.33 & 90.27 & 196.19 & 3.70 & 4.99 & 28.40 & 3.08 & 42.5 \\
\hline Sardegna & NA & NA & NA & NA & NA & 19.48 & 2.33 & NA \\
\hline Italy & 159.40 & 68.13 & 153.87 & 5.91 & 6.10 & 21.87 & 1.73 & 49.4 \\
\hline
\end{tabular}

NA not available 
mental disorders, although a north to south gradient was not observed, being higher in Liguria and Friuli (north of Italy) and lower in Lombardy (north), Tuscany (north), Umbria (centre), Marche (centre) and Basilicata (south). On average, in Italy there were 150 individuals per 10,000 population under the care of mental health outpatient facilities, with wide regional differences, and 6 individuals per 10,000 population under the care of day treatment facilities (Table 3).

In terms of bed use, there were slightly more than 20 admissions to general hospital beds per 10,000 population, with substantial variability in terms of proportion of patients with an outpatient visit within 30 days after discharge, ranging from nearly $90 \%$ in Trento (north) to less than $35 \%$ in Veneto (north), 32\% in Abruzzo (centre) and $30 \%$ in Umbria (centre). The rate of compulsory admissions was 1.73/10,000 population, ranging from 5.68 in Marche (centre) to 0.22 in Bolzano (north) and 0.43 in Friuli (north). On average, there were 6 admissions to community residential facilities per 10,000 population, with substantial variability. Interestingly, the average length of stay in these facilities was higher than 750 days, ranging from 30 days in Campania (south) to 2269 days (more than 6 years) in Veneto (north).

\section{Data-based considerations on the Italian experience}

It has often been emphasised the closing of mental hospitals as the main objective of the Italian reform, while its first and main aim is that individuals with mental disorders are treated the same way as individuals with other diseases. Implementing this principle has determined a shift in the role and focus of psychiatry, from custody and coercion to treatment and care. All the practical changes to the Italian mental health system have been a consequence of this paradigm shift: the total dismantling of old asylums, the development of psychiatric wards in general hospitals and the implementation of a community-based system of mental health care.

\section{Compulsory admissions and suicides}

A hard indicator of the shift from custody to care is a progressive decline in compulsory admissions, both in terms of absolute numbers and in terms of proportion of psychiatric admissions that were involuntary. In other countries different trends have been observed. In the United Kingdom, for example, the number of uses of the Mental Health Act has been rising, with the highest ever yearon-year rise (10\%) to 58,400 detentions in 2014/15 [17]. More than half of admissions to psychiatric hospitals in England are now involuntary, the highest rate recorded since the 1983 Mental Health Act, with wide local variations [18].
A decreasing availability of psychiatric beds has been suggested as one explanation for the rise in compulsory admissions [19]. On similar grounds, in the United States a decreasing availability of psychiatric beds has been suggested as one explanation for the rise in suicide rates [20-23]. The natural experiment offered by the Italian reform would suggest that a direct and linear relationship between psychiatric bed availability and these public health indicators should not be expected. Despite a dramatic decrease in acute-care hospital beds, compulsory admissions decreased and suicide rates remained stable. Data from other G7 countries would reinforce this point, as there are countries with high rates of both beds and suicides, countries with low rates of beds and suicides, and countries with diverging rates. Of course we acknowledge that a wide variety of social, economic, health, mental health and context variables may significantly affect such indicators, and therefore no causal inference can be derived from these descriptive data. However, for the same reasons we argue that increasing the number of psychiatric beds may hardly be considered an evidence-based public health measure to decrease the rates of suicides and the rates of involuntary admissions.

Data available on individuals placed in forensic facilities from 1978 onwards suggests that the phasing out of mental hospitals has not determined an increase of this population, which has declined. Unfortunately, no data are available on the true prevalence of mental disorders in people placed in Italian prisons. A study conducted in one prison found a prevalence of $19.3 \%$ of one or more diagnostic and statistical manual of mental disorders, fourth edition, axis I current mental disorders (excluding substance misuse) [24], which seems in line with international estimates [25].

\section{Mental health workers}

Fewer human resources were available in Italy than in other high-income countries. WHO ATLAS showed that the median number of mental health workers per 100,000 population vary from below $1 / 100,000$ population in low-income countries to over 50 in high-income countries [26]. In Italy there were 33 workers per 100,000, which is below the median of $43.5 / 100,000$ population in Europe and below the median of 52.3/100,000 population in high-income countries. The global median is $9 / 100,000$ population, or less than one mental health worker for every 10,000 people [26]. Although it may be argued that the Italian experience suggests that human resources are not as important as system organisation, it is nevertheless true that staff availability is associated with the capacity of providing mental health care which, in turn, affects the coverage for severe mental disorders, which is one of the main targets mentioned by the $\mathrm{WHO}$ action plan [27]. 
Related to this, Italy has the lowest gross domestic product among the G7 countries, with the lowest proportion of government expenditures on mental health. Looking ahead, this may represent a key challenge for the sustainability of the Italian mental health care system, and for the quality of health care provided by mental health services.

\section{Community residential facilities}

In Italy we recorded more beds in community residential facilities as compared with other high-income countries. These are non-hospital, community-based facilities that provide overnight residence for people with mental disorders. Usually these facilities serve individuals with relatively stable mental disorders who require rehabilitation interventions. In Italy both public and private non-profit and for-profit facilities are available. A challenging issue is that a length of stay exceeding 2 years on average, and reaching 6 years in some Italian regions, may suggest that these facilities, rather than focusing on rehabilitation, provide inpatient care and long-stay residential services. This was also suggested by the PROGRES survey, which showed that patients in residential facilities were mostly males, with low education, and with a disability pension in the majority of cases Almost half of the sample surveyed was totally inactive, not even assisting with their facility's daily activities. Extremely low resident turnover emerged as one of the most relevant problems [28-30]. Looking ahead, we argue that the mission and operational definition of residential facilities should be reconsidered, perhaps recognising that for many long-term, disabled patients, these facilities currently represent "homes for life" rather than rehabilitation sites. In this perspective, we recognise some ambiguity in their role, being focus on rehabilitation and care but also on some degree of protection, with a risk of gently switching back to custody as main mission.

\section{Variability in service provision}

In terms of regional differences, we highlighted a marked variation in service provision for different areas of the country, especially between the more wealthy areas of northern and central Italy and the poorer regions of the south. It was particularly worrying to note a marked variation in the proportion of discharged patients seen within a month, which is an indicator of continuity of care between hospital and the community, an aspect that is usually considered quite strong in the Italian mental health care system. Not only wide differences were observed in different areas of the country, but the average percentage of $49 \%$ is well below the average for European countries and for high-income countries, which is 81 and 76\%, respectively [13]. Looking ahead, we argue that continuity of mental health care should receive more attention by policy makers and team leaders who have planning and clinical responsibilities, taking advantage of the recently implemented Italian national mental health information system that may play a key role in monitoring this indicator and in providing data to check if poor continuity of care is associated with other facility-related variables, for example the mental health staffing level [31].

\section{Limitations}

The description of the Italian reform presented here has several limitations. A first problem is that national statistics describing health systems may have some imprecisions that cannot be quantified. However, WHO and OECD data are based on operational definitions to decrease ambiguity and to guide towards a common interpretation. WHO ATLAS, for example, has a glossary of terms to precisely characterise facilities, workers, and all the service use data that were collected [13]. A second issue is that national statistics do not capture the type and quality of care provided by Italian mental health facilities. However, at the end of the 1990s, two consecutive nationwide projects gathered an unprecedented amount of data about residential care and acute inpatient care [28-30, $32]$. On the whole, the data collected highlighted several critical issues, such as a large regional variability in the availability of residential and acute inpatient beds, a delay between symptom onset and first contact with psychiatric services, and a substantial proportion of patients that seem not to receive fully adequate care $[28,29]$. Other studies conducted on large, representative numbers of patients in treatment showed that the quality of mental health care may often be of limited quality [33-35].

\section{Concluding remarks}

Overall, during the last 40 years without mental hospitals, Italy has seen a progressive consolidation of a community-based system of mental health care. The Italian experience would suggest that the number of psychiatric beds may not represent a key factor for public health indicators such as rates of suicides, involuntary admissions, and people placed in forensic facilities. We highlighted, however, reasons for concern, including a decreasing staffing level, a potential use of community residential facilities as long-stay residential services, and lack of community alternatives to acute inpatient admissions. Action is therefore required to reverse these trends. At a national level, the resources allocated to mental health care are lower in Italy than in other high-income countries. Consequently, apart from notable exceptions, the organization of services has remained very similar to that implemented 40 years ago. This does not consider the 
fact that the Italian society has been profoundly changing and the needs of special populations, for example the elderly and adolescents, as well as the needs of new populations, such as economic migrants, asylum seekers and refugees [36], are not receiving enough consideration in current service planning and delivery [37]. Additionally, very few evidence-based specific interventions and treatment modalities, such as early intervention teams for first-episode psychosis, for example, have been implemented. Italy needs to improve what is called 'translational epidemiology' in psychiatry [38].

Policy makers and clinical team leaders, with the involvement of a variety of stakeholders and the wider society, should be able to generate a new and innovative vision for the future of mental health care, motivating all the actors involved to work together, as a team, towards new achievements, aiming for continuous improvement and continuous reinforcement of treatment and care as main mission.

\section{Authors' contributions}

$C B$ and $B S$ conceptualised the study. CB was responsible for data curation. $C B$ wrote the first draft and $C B, D P$ and $B S$ reviewed and edited subsequent versions of the manuscript. All authors read and approved the final manuscript.

\section{Authors' information}

$\mathrm{CB}$ coordinates the activities of the WHO Collaborating Centre for Research and Training in Mental Health and Service Evaluation at the University of Verona, Italy, and conducts research in the field of evidence-based global mental health. DP is resident in psychiatry and Ph.D. student at the University of Verona. BS is a psychiatrist who has made, and continues to make, a major contribution to global mental health, by his sustained and vigorous efforts for the advancement of psychiatry and mental health around the world, and particularly for those who are least able to speak for themselves. BS had the opportunity to work with Franco Basaglia, an Italian psychiatrist who gave impetus to the development and implementation of the Italian reform.

\section{Author details}

${ }^{1}$ WHO Collaborating Centre for Research and Training in Mental Health and Service Evaluation, Department of Neuroscience, Biomedicine and Movement Sciences, Section of Psychiatry, University of Verona, Policlinico GB Rossi, Piazzale Scuro, 10, 37134 Verona, Italy. ${ }^{2}$ Lisbon Institute of Global Mental Health, Rua do Instituto Bacteriológico 5, Edifício Amarelo, 1150-190 Lisbon, Portugal.

\section{Acknowledgements}

Not applicable.

\section{Competing interests}

The authors declare that they have no competing interests.

\section{Availability of data and materials}

The datasets generated and/or analysed during the current study are available in the Organisation for Economic Co-operation and Development (OECD) repository [https://data.oecd.org/], the WHO Global Health Observatory [http://www.who.int/gho/en/], the WHO Mental Health ATLAS-2014 repository [http://www.who.int/mental_health/evidence/atlas/mental_health_atlas _2014/en/, the Italian Central Institute of Statistics (ISTAT) repository [http:// www.istat.it/it/].

\section{Consent for publication}

Not applicable.
Ethics approval and consent to participate

Ethical committee approval is not required for this article.

\section{Funding}

This study was performed without any external support.

\section{Publisher's Note}

Springer Nature remains neutral with regard to jurisdictional claims in published maps and institutional affiliations.

Received: 23 April 2018 Accepted: 25 July 2018

Published online: 31 July 2018

\section{References}

1. Tansella M, De SD, Williams P. The Italian psychiatric reform: some quantitative evidence. Soc Psychiatry. 1987;22:37-48.

2. Tansella M, Williams P. The Italian experience and its implications. Psychol Med. 1987:17:283-9.

3. Saraceno B, Tognoni G. Methodological lessons from the Italian psychiatric experience. Int J Soc Psychiatry. 1989:35:98-109.

4. de Girolamo G, Cozza M. The Italian psychiatric reform. A 20-year perspective. Int J Law Psychiatry. 2000;23:197-214.

5. de Girolamo G, Bassi M, Neri G, Ruggeri M, Santone G, Picardi A. The current state of mental health care in Italy: problems, perspectives, and lessons to learn. Eur Arch Psychiatry Clin Neurosci. 2007;257:83-91.

6. Barbui C, Tansella M. Thirtieth birthday of the Italian psychiatric reform: research for identifying its active ingredients is urgently needed. J Epidemiol Community Health. 2008;62:1021.

7. Amaddeo F, Barbui C, Tansella M. State of psychiatry in Italy 35 years after psychiatric reform. A critical appraisal of national and local data. Int Rev Psychiatry. 2012;24:314-20.

8. Ferrannini L, Ghio L, Gibertoni D, et al. Thirty-five years of community psychiatry in Italy. J Nerv Ment Dis. 2014;202:432-9.

9. D'Avanzo B, Barbato A, Barbui C, Battino RN, Civenti G, Frattura L. Discharges of patients from public psychiatric hospitals in Italy between 1994 and 2000. Int J Soc Psychiatry. 2003;49:27-34.

10. D'Avanzo B, Frattura L, Barbui C, Civenti G, Saraceno B. The Qualyop Project. 1: monitoring the dismantlement of Italian public psychiatric hospitals. Characteristics of patients scheduled for discharge. Int J Soc Psychiatry. 1999;45:79-92

11. OECD. The Organisation for Economic Co-operation and Development. http://www.oecd.org/. Accessed 15 May 2017

12. World Health Organization. Global health observatory (GHO) data. http:// www.who.int/gho/en/. Accessed 15 May 2017.

13. World Health Organization. Mental health atlas 2014. http://www.who. int/mental_health/evidence/atlas/mental_health_atlas_2014/en/. Accessed 15 May 2017.

14. Ministero della Salute. Rapporto sulla Salute mentale anno 2015. http://www.salute.gov.it/portale/news/p3_2_1_1_1.jsp?lingua=itali ano\&menu=notizie\&p=dalministero\&id=2769. Accessed 15 May 2017

15. ISTAT. Istituto Nazionale di Statistica. http://www.istat.it/it/. Accessed 15 May 2017.

16. Corleone F. Relazione semestrale sull'attività svolta dal Commissario unico per il superamento degli Ospedali Psichiatrici Giudiziari. http:// www.penalecontemporaneo.it/upload/Relazione\%20Semestrale.pdf. Accessed 15 May 2017.

17. Care Quality Commission. Monitoring the Mental Health Act in 2015/16. http://www.cqc.org.uk/publications/major-report/monitoring-menta I-health-act-report. Accessed 15 May 2017.

18. Sashidharan SP, Saraceno B. Is psychiatry becoming more coercive? BMJ. 2017;357:j2904.

19. Wall S, Hotopf M, Wessely S, Churchill R. Trends in the use of the Mental Health Act: England, 1984-96. BMJ. 1999;318:1520-1.

20. Allison S, Bastiampillai T, Licinio J, Fuller DA, Bidargaddi N, Sharfstein SS. When should governments increase the supply of psychiatric beds? Mol Psychiatry. 2018;23:796-800. 
21. Bastiampillai T, Sharfstein SS, Allison S. Increasing the Use of Lithium and clozapine in US suicide prevention. JAMA Psychiatry. 2017;74:423.

22. Tyrer P, Sharfstein S, O'Reilly R, Allison S, Bastiampillai T. Psychiatric hospital beds: an Orwellian crisis. Lancet. 2017;389:363.

23. Bastiampillai T, Sharfstein SS, Allison S. Increase in US suicide rates and the critical decline in psychiatric beds. JAMA. 2016;316:2591-2.

24. Carra G, Giacobone C, Pozzi F, Alecci P, Barale F. Prevalence of menta disorder and related treatments in a local jail: a 20-month consecutive case study. Epidemiol Psichiatr Soc. 2004;13:47-54.

25. Fazel S, Hayes AJ, Bartellas K, Clerici M, Trestman R. Mental health of prisoners: prevalence, adverse outcomes, and interventions. Lancet Psychiatry. 2016;3:871-81.

26. Lora A, Hanna F, Chisholm D. Mental health service availability and delivery at the global level: an analysis by countries' income level from WHO's Mental Health Atlas 2014. Epidemiol Psychiatr Sci. 2017;13:1-12.

27. World Health Organization. Mental health action plan 2013-2020. Geneva: WHO; 2013.

28. de Girolamo G, Picardi A, Santone G, et al. The severely mentally ill in residential facilities: a national survey in Italy. Psychol Med. 2005;35:421-31.

29. de Girolamo G, Picardi A, Micciolo R, Falloon I, Fioritti A, Morosini P. Residential care in Italy. National survey of non-hospital facilities. Br J Psychiatry. 2002;181:220-5.

30. Picardi A, Lega I, Candini V, Dagani J, lozzino L, de Girolamo G. Monitoring and evaluating the Italian mental health system: the "Progetto Residenze" study and beyond. J Nerv Ment Dis. 2014;202:451-9.
31. Lora A, Lesage A, Pathare S, Levav I. Information for mental health systems: an instrument for policy-making and system service quality. Epidemiol Psychiatr Sci. 2017;26:383-94.

32. de Girolamo G, Barbato A, Bracco R, et al. Characteristics and activities of acute psychiatric in-patient facilities: national survey in Italy. Br J Psychiatry. 2007;191:170-7.

33. Dell'Acqua G, Norcio B, de Girolamo G, et al. Characteristics and activities of public psychiatric inpatient facilities: a national survey in Italy. Giornale Italiano di Psicopatologia. 2007:13:26-39.

34. Lora A, Monzani E, Ibrahim B, Soranna D, Corrao G. Routine quality care assessment of schizophrenic disorders using information systems. Int J Qual Health Care. 2016;28:728-33.

35. Lora A, Conti V, Leoni O. Rivolta A728-733. Adequacy of treatment for patients with schizophrenia spectrum disorders and affective disorders in Lombardy, Italy. Psychiatr Serv. 2011;62:1079-84.

36. Miller KE, Rasmussen A. The mental health of civilians displaced by armed conflict: an ecological model of refugee distress. Epidemiol Psychiatr Sci. 2017;26:129-38.

37. Priebe S. A social paradigm in psychiatry — themes and perspectives. Epidemiol Psychiatr Sci. 2016:25:521-7.

38. Weissman M. Translating epidemiology in psychiatry: the future is here. Epidemiol Psychiatr Sci. 2012;21:167-9.
Ready to submit your research? Choose BMC and benefit from:

- fast, convenient online submission

- thorough peer review by experienced researchers in your field

- rapid publication on acceptance

- support for research data, including large and complex data types

- gold Open Access which fosters wider collaboration and increased citations

- maximum visibility for your research: over 100M website views per year

At BMC, research is always in progress.

Learn more biomedcentral.com/submissions 